\title{
Review Usability of Facilities for Visually Impaired People in Sri Lanka Case Study of Bambalapitiya- Kollupitiya Section
}

\author{
W. K. Mampearachchi and L.D.U.N. Liyanage
}

\begin{abstract}
Accessibility protects the basic rights of a human being such as the right to receive facilities like healthcare, education and the right to do an occupation to earn one's living etc. Therefore it is essential to develop a barrier free road environment that guarantees accessibility for all. Accessibility for differently abled people is not a new concept to the world. There are many related codes and practices in other countries. Sri Lanka has recently introduced this concept to the road infrastructure by improving the Bambalapitiya - Kollupitiya road section as disabled friendly.
\end{abstract}

The study team has reviewed international guidelines on designing facilities for blind and visually impaired people. The study team has also observed the behaviour of two trained blind personal while they were utilizing the tactile guide way at Bambalapitiya - Kollupitiya road section. A video clip was produced to further analyze their behaviour and review the usability of the facility. Several problems have been identified in the new facility. Most importantly when compared with guidelines which have been followed [3], there were deviations of construction due to faulty workmanship and lack of details mentioned in the document. Comments of two people were noted regarding their personal experience and their suggestions for further improvements.

It was found that the guidelines [3] have been prepared neither with proper understanding of visually impaired people nor the suitability of the design for the road environment in our country. After considering all these facts, the study team was able to modify some guidelines and even come up with new standards for the Sri Lankan condition. The study team has proposed new layouts for pedestrian walkways and bus stops considering the needs of both visually impaired and mobility impaired people.

Key words: Accessibility, Differently abled people, tactile, visually impaired, mobility impaired.

\section{Introduction}

Differently abled people may lack certain abilities, but they may exceed an average person in special abilities. So it is important not to neglect this group of people. They should be able to gain education, receive health care facilities which are the basic needs of a human being or even join country's work force by having an occupation. Accessibility is the key to all of this.

Currently not much consideration is given to accessibility for differently abled people in Sri Lanka. But as an initiating step, the Colombo Municipal Council has improved Bambalapitiya - Kollupitiya road section as disabled friendly. They have followed guidelines given in the Gazette of
Democratic Socialist Republic of Sri Lanka [3].

In this road section, special attention was given to visually impaired people. An orderly layout was given to the pedestrian walkway. A tactile guide way has also been introduced.

Eng. (Dr.) W. K. Mampearachchi, BSc.
Eng.(Hons.)(Moratuwa), MSCE (South Florida), PhD
(Florida), CMILT (UK), Senior Lecturer, Department of
Civil Engineering, University Moratuwa, Katubedda,
Moratuwa, Sri Lanka.
Eng. L. D. U. N. Liyanage, Engineer, State Engineering
Corporation, Sri Lanka




\subsection{Significance of the Problem}

Sri Lanka is a country which has been affected from war for many years and disability is one of its tragic consequences. People who were once called war heroes are also among them. To ensure a dignified living, facilities should be provided for these prople to live independently. Hence improvement in accessibility is a must.

Generally when there is a differently abled person in a family, additional expenditure has to be made for medical, educational, transportation and other requirements. Therefore such families have to face financial difficulties. Usually differently abled children from low income families are deprived from education since public transportation is not accessible for them or they cannot afford to use expensive transport modes. Children growing up uneducated will not be able to make a living by doing a job. So other family members have to take care of them. This is a vicious cycle where such families can never improve their standard of living.

\subsection{Objectives}

With the understanding of the necessity of a barrier free road environment for differently abled people, Colombo Municipal Council has improved Bambalapitiya - Kollupitiya road section as disabled friendly. They have followed guidelines given in the Gazette of Democratic Socialist Republic of Sri Lanka [3]. Before using this set of guidelines, for further improvements, it is necessary to examine the existing facility to see if there are faults in constriction or design itself. It is also possible to find better solutions which would be appreciated more by the differently abled people in Sri Lanka.

\section{Present Practices and Standards}

Currently the guidelines given in the Gazette of Democratic Socialist Republic of Sri Lanka [3] are being used to develop differently abled facilities. It covers different areas such as dimensional data of a wheel chair user, standards of pathway dimensions, gradients, surface condition, tactile paving, details of kerb ramps and their arrangement at crossings, layout at bus stops and car parks, etc.

When referring documents such as RTS 14 Guidelines [2], ESCWA design manual [1], TRL Overseas Road Note 21, [4] it can be seen that all of them are based on same principles with small variations. Local guidelines [3] are also based on the same principles such as providing maneuvering space and safer gradients for wheel chair users, providing artificial guidance and warnings to visually inspired people etc. But it is a very brief document where detailed descriptions are missing. The documents RTS 14 Guidelines [2], ESCWA design manual [1], TRL Overseas Road Note 21 [4] included finer sketches and thorough explanation for each guideline which prevents us from blindly following them. This is one of the problems in Sri Lankan practice. There were many unreasonable inclusions in the differently abled facility in Bambalapitiya - Kollupitiya road section for example, tactile warning pavers fixed at small bumps along walkway since the guidelines say to use tactile warning to warn against drop-offs.

The video "Pathway to independence" from "Nebraska Commission for the Blind and Visually Impaired" [5] is a helpful tool for understanding the abilities of a blind person, identifying the cues they use for environmental orientation and understanding the techniques they use in white cane travelling.

Documents such as: ESCWA design manual [1], TRL Overseas Road Note 21, [4] were helpful for understanding difficulties faced by differently abled people. That includes sidewalks, pedestrian crossings, bus stops and car parks.

Furthermore, sets of guidelines developed by various institutions (NZ Transport Agency [2], ESCWA [1] and DFID [4]) and local set of guidelines [3] were thoroughly examined to get a good understanding of the designs of differently abled facilities worldwide. The international standards gave a proper explanation for its guidelines and had fine sketches. ([1], [2], [4]) Guidelines of each of these documents were compared carefully. 


\section{Methodology}

The study team has reviewed the available standards and guidelines for developing differently abled facilities. The characteristics and performances of the tactile facilities have been reviewed. The study team has also observed the behaviour of visually impaired people while they were utilizing the facility.

From this study, the study team was able to identify the following:

- How a visually impaired person uses his instinct to guide along the tactile guide way.

- How the facility benefits a visually impaired person for convenient and safe movement.

- Difficulties they face due to short comings of design.

- How the facility can be improved to provide more safety and convenience to the users.

Two retired army officers with visual impairment joined this study. Both of them have been coping with total blindness for more than 10 years, and have considerable experience facing life with their difficulties. Despite their hardships, they actively participate in social activities as any other person. Therefore, they are skilled in white cane travelling. For the purpose of study, a certain section of road was selected and the two officers were asked to walk along the sidewalk with the aid of their white canes. First, they were asked to identify the three different types of textures present in tactile guide way, tactile warning and rest of the surface of sidewalk by making them sense by their feet. Then, a brief description was given about the layout of sidewalk including how tactile pavers, street poles, bus stops, street crossings etc are arranged. The study team used a physical model as shown in Figure 1 to convey the details further. Then they were able to identify how each feature was located along the side walk, how the tactile guide way led them to each feature, how the features can be identified by certain cues etc.

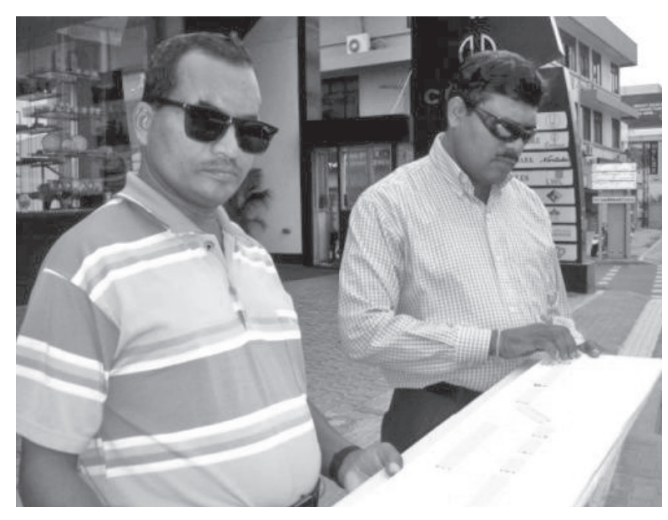

Figure 1 - Physical Model of the Layout of Sidewalk with Tactile Paving.

Initially they were asked to walk a certain distance along the tactile guide way, with the guidance of the study team, in order to become familiar with the road environment. After that, they were asked to walk on their own guided only by the tactile guide way. For safety reasons, one person had to walk beside them. Finally their behaviour was recorded in a video.

\section{Data Analysis}

Initially, the two officers found difficulty following the tactile guide way but afterward they adapted to the new environment and were able to walk considerable lengths in right tract without our aid.

According to the observations during the study, the study team was able to understand how a visually impaired person uses his/her instinct to guide along the tactile guide way, how the facility benefits a visually impaired person for convenient and safe movement, difficulties they face due to short comings of design, and finally, suggest improvement to enhance safety and convenience to users.

\subsection{Characteristics of the Tactile Guide Way in the Perspective of a Visually Impaired Person}

- When a blind person walking along the tactile guide way has reached a point of tactile warning, he/she can think of several possibilities. It can be a point of directional change, edge of an entrance, place where side walk crosses a byroad, pedestrian crossing, top or bottom of a slope or a bus stop. 
- First, he/she can slide the cane in front of him/her and if the tactile warning exists in a wider range than the width of the tactile guide way, it can be a place where sidewalk crosses a by-road. Then he/she can tap on ground to check whether asphalt paving can be detected.

- When sliding cane, if it was found that the tactile warning extends only in one direction, there are two possibilities. It can be a bus stop or a pedestrian crossing.

- Then, he/she can swing the cane in the direction where the tactile warning extends, and if a traffic signal post was detected, it can be a pedestrian crossing. Then, he/she can touch the post to check whether a box with the pedestrian push button can be detected.

- When swinging the cane if he/she couldn't find a traffic signal post, it can be a bus stop. Then, he/she can swing the cane to check whether any pole can be detected. It may be a pole of bus stop shelter or a bus stop sign pole.

- When sliding the cane, if he/she could find that the tactile warning is only limited to the width of the tactile guide way, he/she can think of following possibilities: It can be a point of directional change, edge of an entrance or top or bottom of a slope.

\subsection{Review of the Performance of Facility}

According to the observations of the behaviour of participants travelling along the tactile guide way and review of standard of specifications, authors were able to list pros and cons of the design as following:

\section{- Aesthetics of design}

The newly constructed sidewalk was aesthetically pleasing and it enhances the beauty of the city. Therefore, development of such a standard could be encouraged.

\section{- Good color contrast}

It is observed that the color of tactile pavers was in good contrast with the surrounding color. Tactile pavers were yellow in color and the surrounding blocks were dark red. This color contrast may benefit people with poor vision.

\section{- Deviation from convention}

Blind people including these two officers have developed their skills on white cane travelling based on conventional methods. The conventional methods are based on the nature of existing road infrastructure. Therefore, people should have to change to adapt to the new facility. When travelling in an ordinary side walk they use kerb line as a natural guide line or edge of the pavement if it is a rural road. They differentiate grass, soil, pavement etc. by tapping. They identify each material by the reflected vibration through sense in hand or listening to the reflected sound.

"While they are walking they swing the white cane in an arc about the width of the shoulder or a bit wider keeping one's self at center of the arc and tap either side of the arc."

But when travelling in tactile guide way they have to switch to sweeping arc method. That is sliding the tip of the white cane across the ground surface in an arc. That allows differentiating texture of tactile pavers from surrounding surface.

\section{- Difficulty in differentiating textures}

As the two officers followed the tactile guide way they started to travel off track at some locations. They told that they had difficulty differentiating the tactile pavers from the surrounding pavers. They told it would be better if there was more extrusion in tactile pavers. But according to TRL road note 21 [4] standards, an average blind person can detect extrusions of $5 \mathrm{~mm}$ with the aid of a white cane and extrusions more than that should be avoided since it will cause difficulty to wheel chair users. Not only that the blind people themselves may trip off. So it is not suitable to use tactile pavers with greater extrusions. However we noticed that there was deficiency in grouting so the spaces in between the paving blocks has given a texture that causes difficulty to differentiate tactile pavers from the surrounding. Figure 2 shows the surface texture of the tactile and the surrounding. 


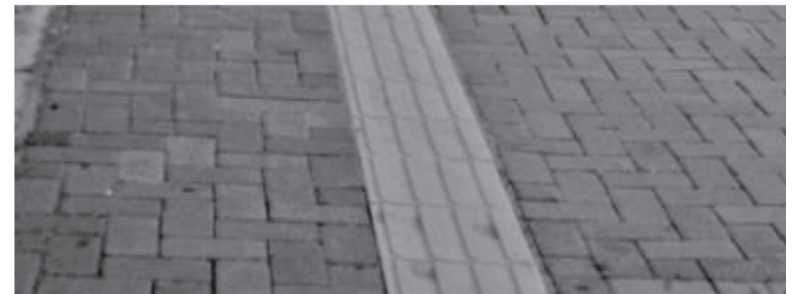

Figure 2 - Similar Texture in Tactile Guide Way and Surrounding Surface

Therefore quality control was proven to be essential in such developments. When developing new guidelines we should especially emphasize that the surrounding surface shouldn't have grooves giving a texture somewhat similar to the texture of the tactile guide way unless the voids are properly grouted. It is essintial to have a smooth texture in the surrounding surface.

\section{- Crossing a by-road}

At intersection points of by-roads there is no continuation of the side walk across it and so do the tactile guide way. At one point when we let the blind person cross the by-road on their own he tend to move towards the main road rather than walking straight across the crossing. That was really dangerous. The reason behind this incident is believed to be the difference in angle between the line that is perpendicular to the kerb line and direction of crossing. See figure 3. The black arrow indicates the direction of crossing while the red arrow indicates direction perpendicular to kerb line.

It was not the same when crossing the main road because they can detect the kerb line and walk perpendicular to that straight edge and move in the correct direction. Here the authors emphasize the importance of preparing guidelines taking such fine details in to consideration.

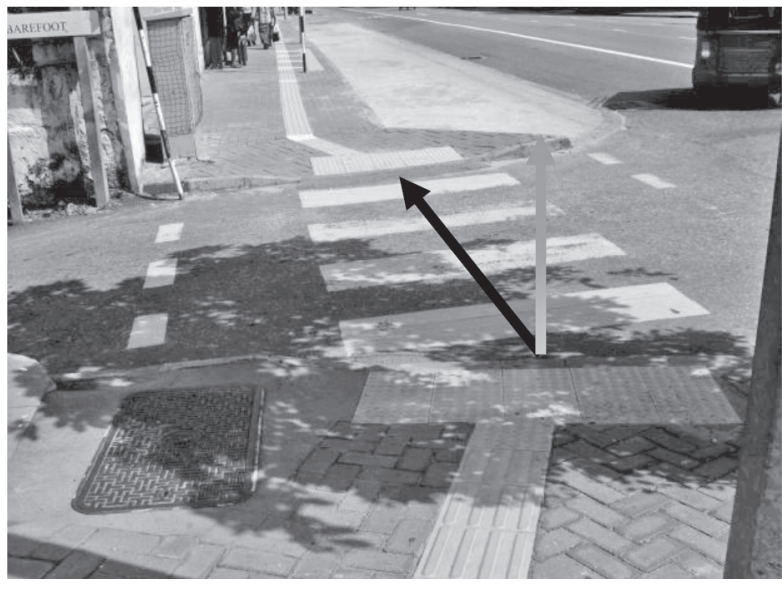

Figure 3 - Unacceptable Layout of a Road Crossing

But in certain locations the tactile guide way continued across by-road. That was beneficial. For safety reasons there was tactile warning at both ends of the crossing. Besides that, the drivers from the by-road are also aware of the possibility of a blind person crossing the road. So they can be cautious when entering the main road. See figure 4

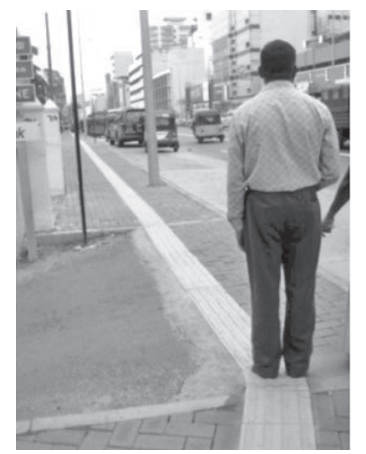
Figure 4 - Tactile Guide Way across a By-
Road

- Consistency in layout of the sidewalk Consistency of sidewalk layout is very important for a blind person so that he could easily keep things in memory and do predictions. Therefore, he can walk much faster with greater confidence. Identifying his/her exact location as well as locating the desired destination will be much easier.

Both sign poles and light posts seem to have arranged in a straight line. The tactile guide way was in parallel with that line with enough distance in most sections. Other obstructions such as: bus stop shelter poles, advertising boards were also placed 
at sufficient distance from the tactile guideway. Because of that there is a clear width centering the tactile guide way that ensures safe movement of a blind person. See figure 5.

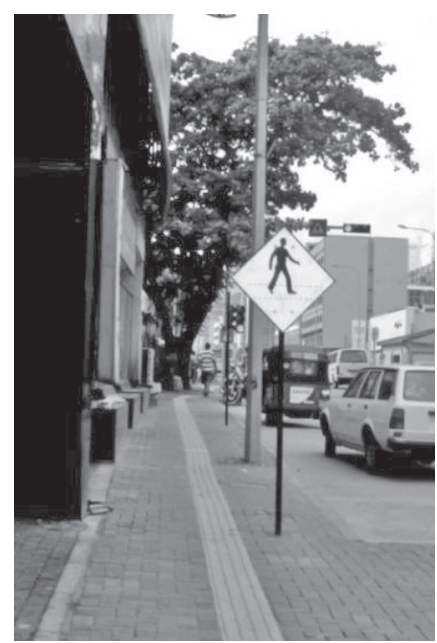

Figure 5 - Light Posts and Road Sign Poles in a Straight Line

Tactile warning was present at either end of an entrance or whenever the sidewalk crosses a by-road. In addition to that at any place where there was a sudden slope or where the tactile guide way changed the direction there was tactile warning. Tactile paver arrangement at bus stops (See figure 6) or street crossings (See figure 7) also had a pattern.

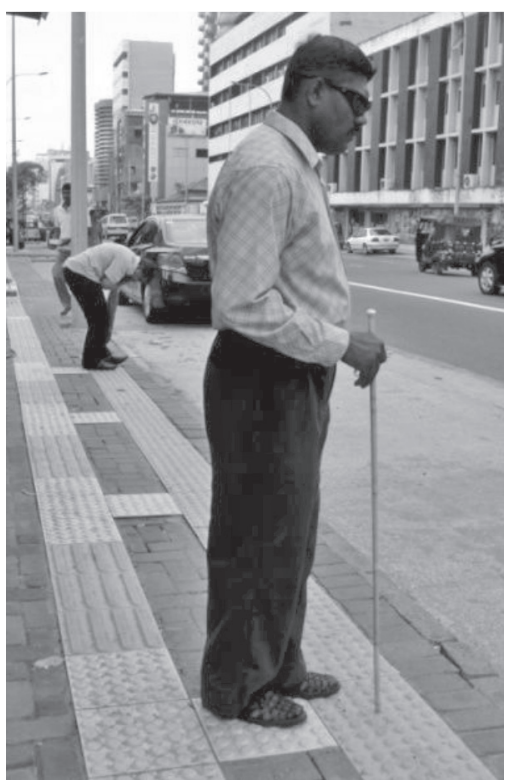

Figure 6 - Tactile Paver Arrangement at a Bus Stop

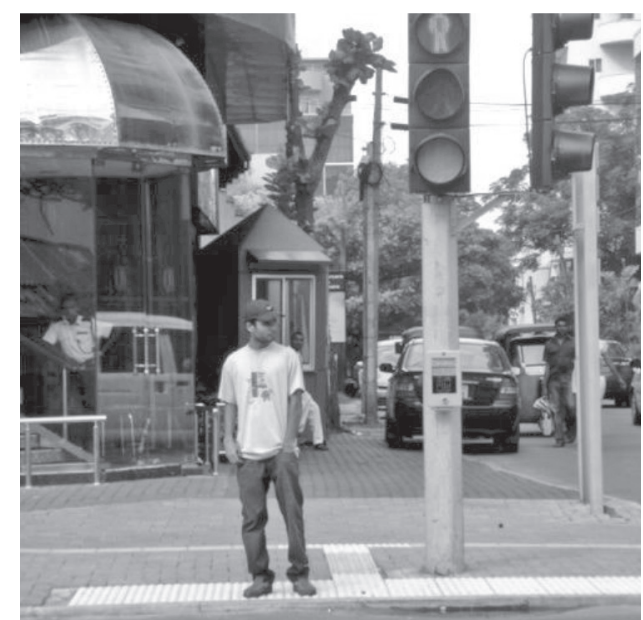

Figure 7 - Tactile Paver Arrangement at a Pedestrian Crossing

At bus stops, other than the tactile paver arrangement the shelter, seat, and the position of bus stop sign pole seemed to be in a specific pattern. Same type of shelter and seat were used in each bus stop. The bus stop sign pole was always at the right end of the bus stop when facing the road as shown in Figure 8.

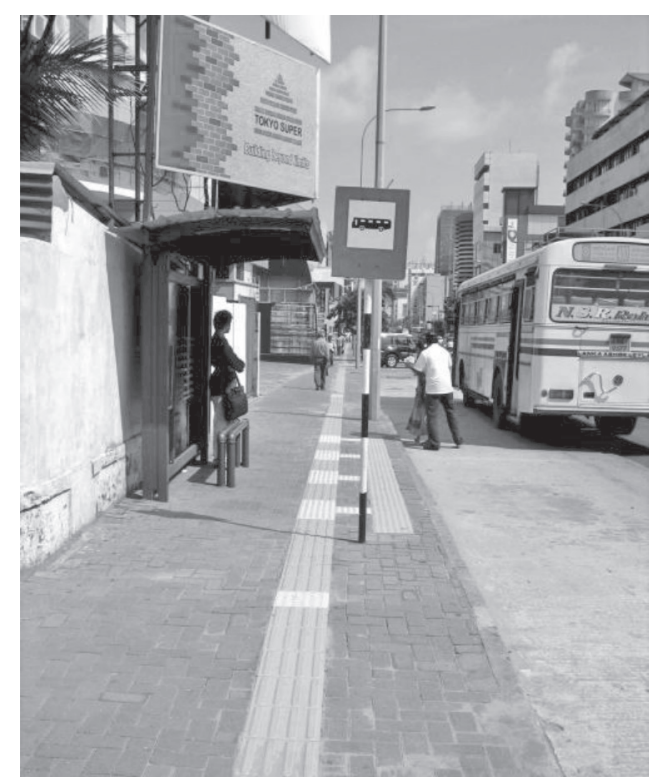

Figure 8 - Consistency of Bus Stops

- Deviation of the pattern

Again the study team has found the importance of supervision and accuracy of the design details during the construction phase due to slight deviations from expected patterns. Such changes can be extremely dangerous in certain situations. 
Therefore, a road improvement of this nature needs to be perfect. When a blind pedestrian is walking in a tactile guide way he/she will follow the patterns with confidence expecting no faults, Therefore when he/she encounters any dangerous situation he/she will not be prepared. An ordinary road will be better than an improved road in that sense because then the person would travel with caution avoiding possible danger.

It was observed that there is a slight variation of tactile paver arrangement at a street crossing. Again it was observed that the traffic signal post at one crossing has been in the right side of the person crossing the road, while it has been in the left side in another crossing. Changes of this nature may not be considered as dangerous but they could cause confusion to a blind person.

At one location the shelter of the bus stop was away from the tactile marking (See figure 9) and in another location there was a light post in between the tactile marking of the bus stop and bus stop sign pole. Arranging features in a consistent pattern can be very important. For example bus stop shelter and bus-stop sign pole can be arranged in the same pattern so that they can be used as cues for easy identification of a bus stop. The bus-stop sign pole can also be used to give information such as the route number in tactile form. Furthermore a blind person will be able to find the seat easily. When things are not in the correct order such as mentioned above the blind person may get confused.

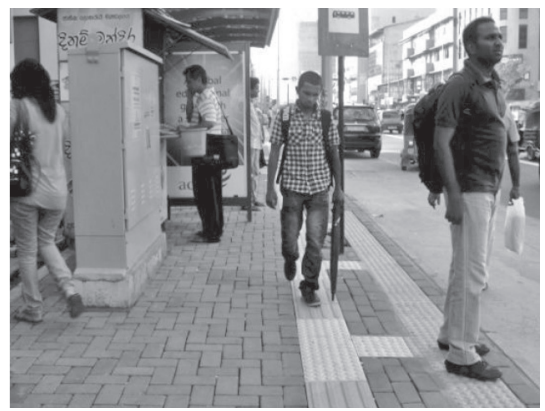

Figure 9 - Deviations of Pattern at Bus Stops

In most sections the tactile guide-way was straight but there were several points where it changed direction and tactile warning was present at each of those points. Frequent changes in direction can confuse a blind person it could cause difficulty for him to keep track of environmental orientation. Tactile warning is present at many other locations such as at bus stops or street crossings besides at points where tactile guide-way changes direction. Therefore, when each time he comes across a tactile warning he has to spend some time to differentiate among them. Because of these reasons changes in direction should be minimized as possible or warning sign should be used around such obstructions. At several locations directional change was unavoidable but in other places they could have construct the tactile guide way straight. Figure 10 shows the avoidable and unavoidable obstructions in tack tile guide-way.

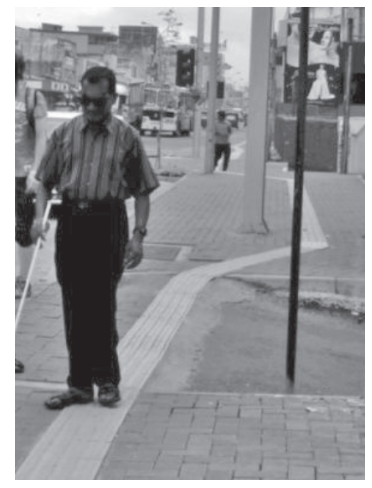

(a) Avoidable

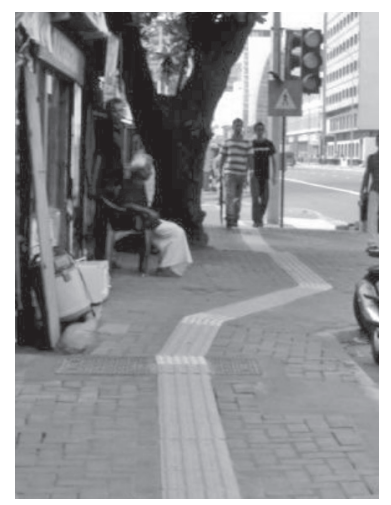

(b) Unavoidable

Figure 10 - Change in Direction

- Unacceptable tactile layout at bus stop At a bus stop there were several points of tactile warning which directed people to boarding area (Figures $6,7 \& 8$ ). Even if it gives a unique layout of tactile indicator at 
a bus stop, two officers who joined the study were unable to identify it as a bus stop. They have confused the tactile warning at the bus stop with many other situations where tactile warning was given. Having a longer boarding area will prevent them from getting directed exactly to the entrance of the bus. The designers have marked several entrance points in the bus bay. It is not advisable to have too many entrance points. One such entrance should be clearly marked in tactile indicator and the bus crew should be trained to stop the bus such that the entrance of the bus is in line with the tactile guide.

\section{- Unnecessary warning}

Tactile warning was present at ends of either side of entrances. In addition, tactile warning has been given when there were slopes of the side walk surface. As mentioned above too many tactile warning can confuse a blind person so they should be minimized as much as possible. According to the personal experience of two officers a blind person can manage to walk in small slopes safely without warning. Participants' opinion is that tactile warning was not necessary in most locations. At some places tactile warning was given for bumps on sidewalk surface. Instead of providing tactile warning they should have leveled off the side walk surface. When there are steep slopes tactile warning should be given at both bottom of the slope and top or otherwise the slope could be reduced if ground was sloped in a longer span. Figure 11 shows the tactile warning at top and bottom of a mild slope.

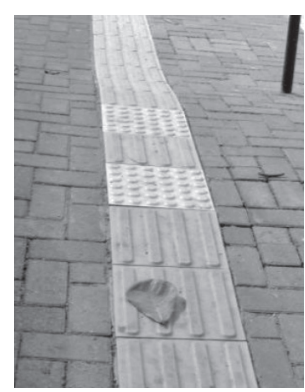

Figure 11 - Unnecessary Tactile Warning at a Mild Slope

\section{- Safety hazards}

Seats of the bus stops are not suitable especially for a bus stop in a road section which is designed for visually impaired people. They can cause danger to a blind person. Figure 12 shows an unsafe bench in the bus-stop.

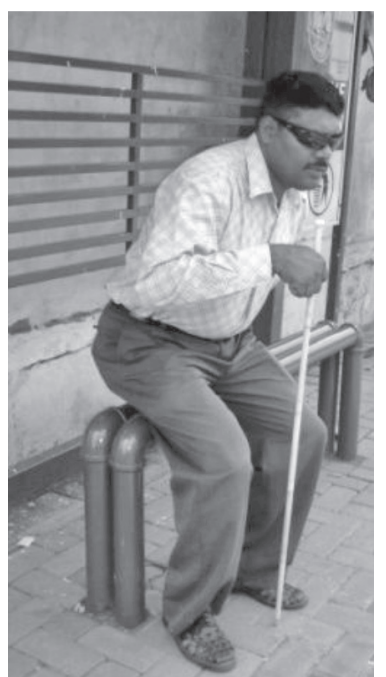

Figure 12 - Safety Hazards

\subsection{Suggestions for Improvement}

After reviewing the literature and observations of field study, following improvement are listed to make the facility more beneficial to the visually impaired people.

\section{- Places for Rest}

Providing places for rest is important since most differently abled people neither can walk long distances nor stand for prolonged time. According to Veter et al [4] wheel chair users and vision impaired people need to rest at intervals not more than $150 \mathrm{~m}$. For mobility impaired people the interval is less than this value, therefore, places for rest should be located at intervals not more than $150 \mathrm{~m}$. According to Veter et al [4] about $50 \%$ of people with disabilities can stand for less than 10 minutes. So places for rest should also be provided in places such as bus stops where people have to wait for long periods. The public seats and benches approximately $0.45 \mathrm{~m}$ above floor level, with backrests at approximately 0.70 $\mathrm{m}$ above floor level and a minimum space of $1.20 \mathrm{~m}$ should be reserved for a wheelchair beside the seat or bench. Always the place of resting should be 
located as the free passage of other pedestrians is not obstructed.

\section{- Tactile guide way}

No matter how much artificial guidance is provided a visually impaired person should always be alert of danger. There can be temporary obstructions such as: garbage, baggage, fallen tree branch etc. So he/she must always sweep their cane across the floor in front of them. Therefore in some cases we can avoid providing tactile guide way. Tactile guide way is not essential in locations such as along the sidewalk in a straight section with sufficient clear width and obstructions located in a consistent pattern in one continuous line. However, there should be enough natural guidance such as the kerb line to stay in right track. In such a case tactile warning around obstacles is required.

Visually impaired people need artificial guidance such as tactile guide way especially where a natural guideline is not present. Edge of the footway or building base may provide guidance but in places such as where footway crosses large openings artificial guidance is necessary for the continuity of the guideline. Tactile guide way may also be needed to designate the continuous accessible route to be taken to avoid hazards or to give directional orientation to a person who must deviate from the continuous accessible path to gain access to a crossing point, public transport access point, or point of entry to a significant public facility e.g. public toilet, information centre etc.

Tactile guide way should have a line type texture as the lines are in the direction in the path of travel. Tactile guide way should be parallel with and along the centerline of the required direction of travel and have a minimum width $300 \mathrm{~mm}$. There should always be at least $900 \mathrm{~mm}$ clear width along the travel path. Providing a clear spacing of $1200 \mathrm{~mm}$ is much better to facilitate easy movement of a wheel chair user and another person walking in side. [1], [3], [4]

In a situation where the person should deviate from the continuous accessible path to gain access to a crossing point, public transport access point etc. The tactile guide way should be across the full width of the path way to avoid the person from passing without detecting warning. This is when no tactile guide way is provided along the travel path. See Figure 13.

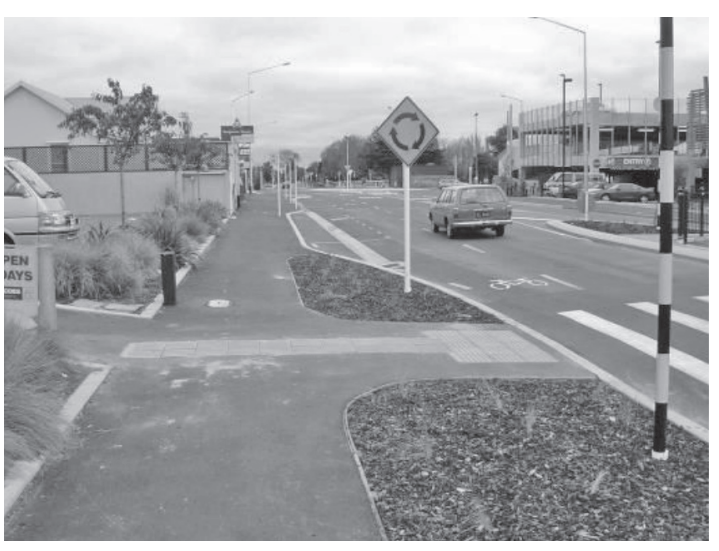

Figure 13 - Tactile Guide Way Cover the Full Width of the Path

But if there is a tactile guide way along the travel path there should be a tactile warning zone at the junction of main guide way and deviated guide way.

\section{- Tactile warning}

Tactile warnings are intended to function much like a stop sign. They warn pedestrians who are vision-impaired to hazards in their line of travel, indicating that they should stop to determine the nature of the hazard before proceeding further. They do not indicate what the hazard will be. Therefore, providing tactile warning for many different purposes will confuse a visually impaired person. Therefore, use of tactile warning should be limited to critical safety hazards only.

Tactile warning is necessary when the tactile guide way leads to a dangerous situation like; a pedestrian crossing, the height restricted space under a stair way, top or bottom of a stair way, when the sidewalk crosses a by-road or a vehicle moving entrance to a building etc

Obstructions should be easily detectable for the benefit of sightless. Whenever there is an obstruction that can't be removed such as a telephone booth it should either be on a raised plat form or surrounded by tactile warning blocks so that a visually impaired person can detect it through his white cane. If tactile warning is used, it is better to 
extend it at least $600 \mathrm{~mm}$ outside the projected area at the base of the obstacle.

The texture of such warning could be easily differentiated from the texture of the tactile guide-way. Usually, it is a dot type texture. Dimensions of the tactile warning zone should be sufficient so that a visually impaired person will not pass it without detecting. Distance from the further edge of tactile warning and the hazard should be sufficient enough for the safety of the person and it also should not be too much since it may lead to misunderstanding.

\section{- Layout at a pedestrian crossing}

The tactile layout should be Simple, logical and consistent so that people can easily memorize it and that may help them to move faster with more confidence. When designing the tactile layout following factors should be kept in mind. A visually impaired person should be able to:

- Find the crossing point

- Identify when the footpath finishes and roadway is about to be entered

- Determine the direction to cross

- Determine when it is safe to cross

- Maintain orientation while crossing the road

- Find the opposite kerb crossing point.

Tactile warnings should be placed at an edge of a street crossing to warn visually impaired people so that they can know that they are about to step on to the road. Different tactile warning surfaces can be used but better to use the same type of surface throughout the country to avoid confusion. Tactile guide way should be provided to direct visually impaired people to the tactile warning zone when the crossing is not in line with the path of travel. It should act as an indicator of the direction of the crossing. That means the center line of the tactile guide way and the direction of crossing should be same. Edge of the tactile warning zone should be easily detectable and it should be perpendicular to the direction of crossing. Tactile warning and guide way should have sufficient widths to ensure that a visually impaired person will not pass without detecting them. Figure 14 shows the proposed tactile guide-way to direct blind people to crossing in the absence of a guide-way along the sidewalk.

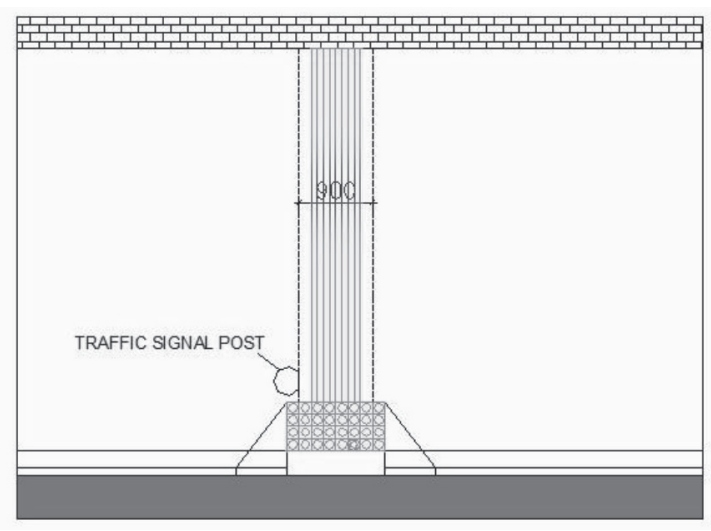

Figure 14 - Tactile Indicators at a

Pedestrian Crossing where no Tactile Guide Way along Travel Path

The signal post should be located right of the tactile guide-way. Figure 15 shows the tactile arrangement at a crossing in the presence of tactile guide-way in the sidewalk.

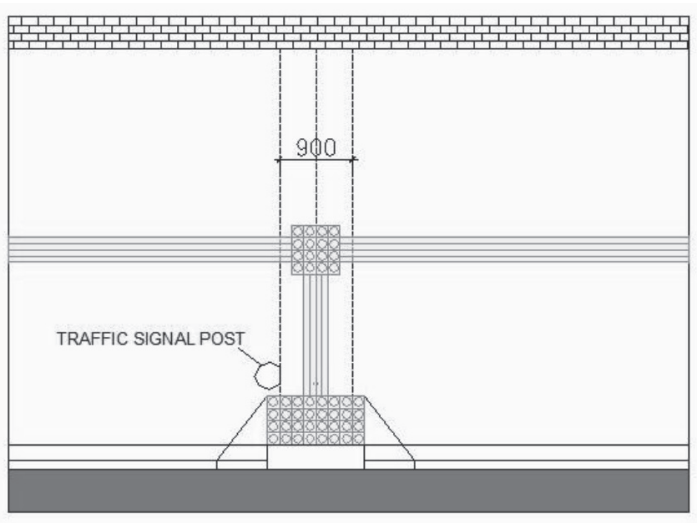

Figure 15 - Tactile Indicators at a Pedestrian Crossing with a Tactile Guide Way along Travel Path

Push button of a traffic signal poles should be at an offset not less than $450 \mathrm{~mm}$ and not greater than $600 \mathrm{~mm}$ from the centerline of the tactile guide way that leads to road crossing and also it should be easily reached by a person waiting on a tactile warning zone. This ensures that the person crossing the road doesn't have to move away from the line of tactile guide way since it is in the range of reach and also there is enough space for the movement of a wheel chair. Now, a blind person can walk in a straight line along the tactile 
guide way and across the road so that he can walk keeping himself in the mid span of the width of the road crossing.

When the road crossing point is at a corner or an intersection and if the corner has a large kerb radius, the continuous accessible path of travel intersects with the curved kerb. Therefore it is difficult to design kerb ramps in the direction of pedestrian crossing and to arrange tactile warning to indicate the direction of crossing. In such a case a bottom landing should be provided as in figure 16.

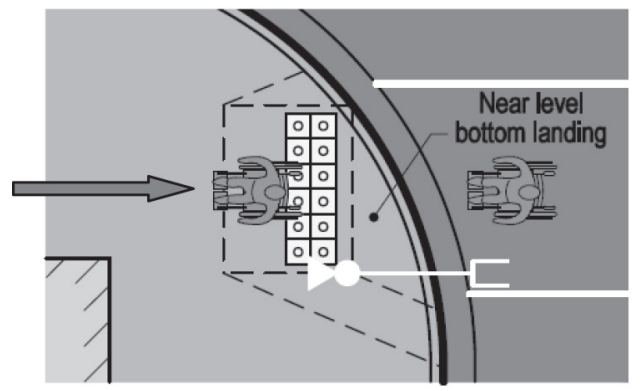

Figure 16 - Correct Bottom Landing Arrangement

Direction perpendicular to edge of warning tactile and the crossing direction are same in the proposed arrangement. Misguiding and safety issues in the tactile arrangement as shown in Figure 3 can be avoided with the tactile layout in Figure 16.

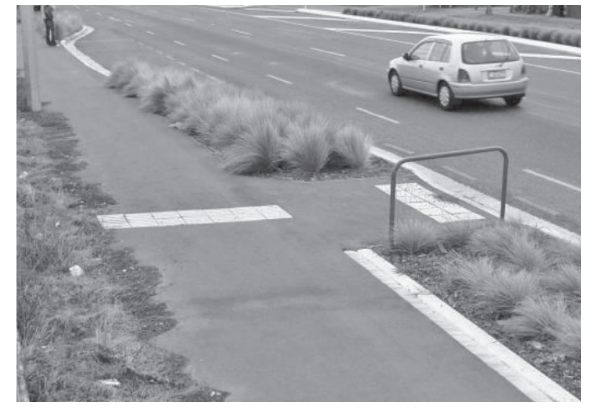

Figure 17 - Tactile Indicator Together With a Handrail Provide Cues to a Road Crossing Point

\section{- Layout at a bus stop}

A sheltered bus stop should have sufficient space for a wheel chair to enter, maneuver and wait. In the same time it should not obstruct the other pedestrians who are passing by. Layout of the bus stop should be simple and consistent and tactile indicators, bus stop pole and bench should be used to provide clues to a visually impaired person to correctly identify it as a bus stop. A handrail next to a road crossing specified in RTS 14[2] (Figure 17) provides a clue to recognize a road crossing. These clues should be in a detectable range of white cane $(600 \mathrm{~mm})$ and should be located as they would not obstruct the travel path $(450 \mathrm{~mm})$. Tactile indicators should have sufficient width $(600 \mathrm{~mm})$ so that a visually impaired person would not pass it without detection.

In figure 17 it can be seen how a handrail is used to direct pedestrian to a road crossing point. Similarly we can use a handrail to direct pedestrian to a bus stop boarding zone. It will also assist vulnerable people who cannot stand for long time.

In case of a bus stop with shelter it is preferred to provide space for the pedestrian movement in the rear side of the shelter better width is $1500 \mathrm{~mm}$ but can take $900 \mathrm{~mm}$ as a minimum value. Otherwise in an area where space is severely restricted shelter can be sited against the rear of the footway. Always a clear space should be provided in between the shelter and street. $1300 \mathrm{~mm}$ width is preferred and $900 \mathrm{~mm}$ can be taken as a minimum. This space is necessary for wheel chair users to accommodate while waiting or boarding a bus. Figure 18 shows the proposed design for sheltered bus stop with a tactile guideway.

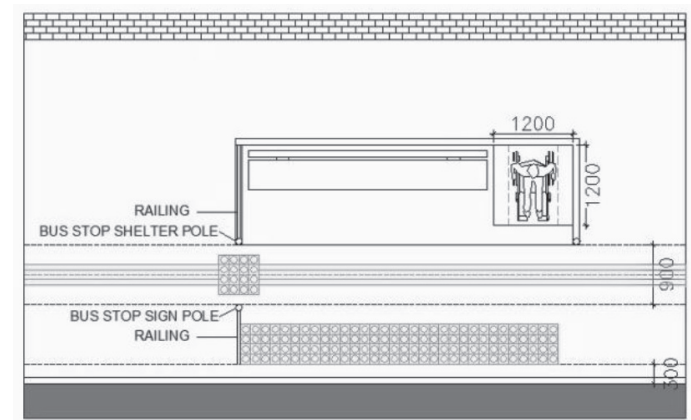

Figure 18 - Layout of a Sheltered Bus Stop with Tactile Guide Way along the Travel Path

When a person is walking along a tactile guide way as in figure 18 and detects tactile 
warning he/she would sweep the white cane in an arc for more cues. If he/she detects bus stop shelter pole and bus stop sign pole he/she can be sure that it is a bus stop. Then he/she can either use the bus stop sign pole and railing to reach the boarding area or use the bus stop shelter pole and railing to reach seat. The location of bus stop sign pole will indicate an exact place for the bus to stop. But if the bus has not stopped in the exact place guidance should be provided for a visually impaired person to find the bus entrance. Therefore, a tactile warning strip as indicated in the figure is necessary. When the layout is as in figure 19, a visually impaired can find his way to get on a bus in the similar way.

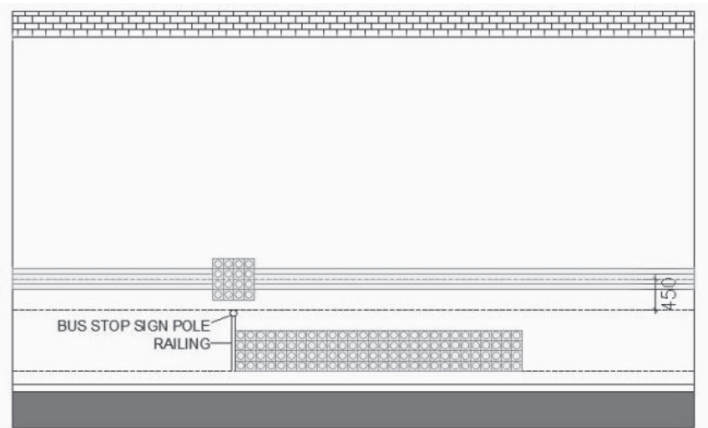

Figure 19 - Layout of a Bus Stop with no Shelter but with Tactile Guide Way along the Travel Path

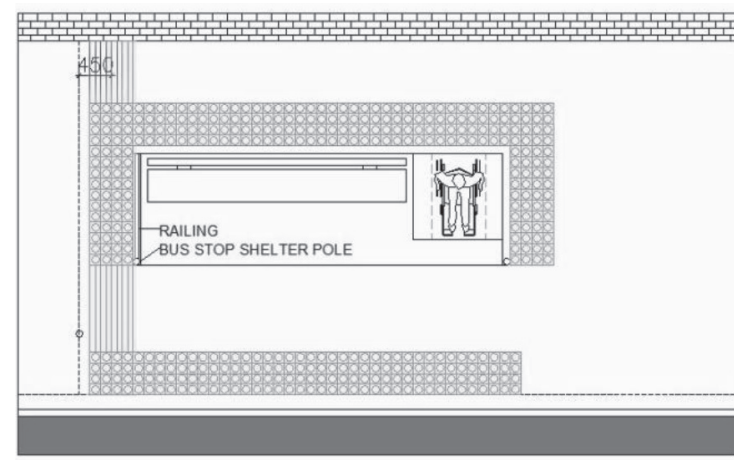

Figure 20 - Layout of a Sheltered Bus Stop with no Tactile Guide Way along the Travel Path

When a visually impaired person is walking in a sidewalk as in figure 20, he/she would either detect tactile warning or tactile guide indicator first. If he/she detects tactile warning he/she should walk around the obstacle and eventually he/she will detect tactile guide indicator. Then he/she must walk along the tactile guide strip towards road so that he/she would detect bus stop shelter pole. He/she can use bus stop shelter pole and railing to reach the seat. When he/she needs to reach the boarding area he/she must use the same tactile guide strip and walk up to the boarding area. When the layout is as in figure 21 a visually impaired can find his/her way to get on a bus in the similar way.

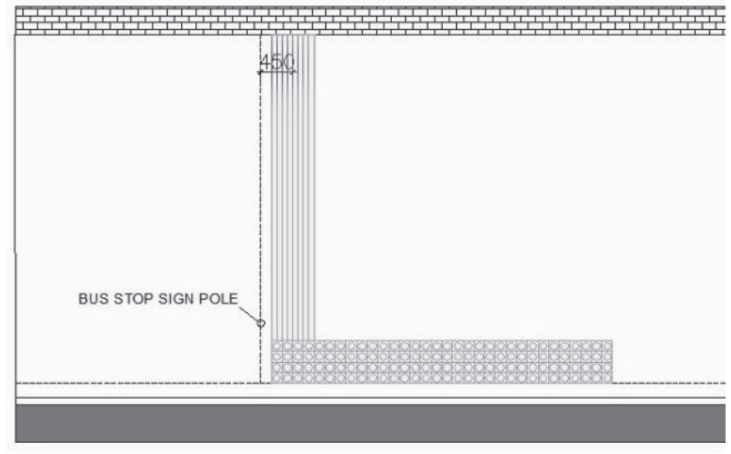

Figure 21 - Layout of a Bus Stop with no Shelter or Tactile Guide Way along the Travel Path

The boarding area of a bus stop should be marked on ground and tactile guide way should direct visually impaired people in to this area. It is better to raise the boarding area up to some extent so that height difference from ground to first step of bus is reduced. It will be helpful for vulnerable people. Whenever possible the bus stop area all together can be gradually raised up to a height of about preferably half the height to the first step of a bus so that the boarding area is also raised. Gradient not greater than 1 to 12 should be provided for ramps.

Introducing bus bulbs will be beneficial so that the bus will be oriented and made to stop in the exact place thus allowing differently abled people get in to the bus easily. In this way, a bus will be able to reach the kerb line even closer since at a bus bulb [4] the footway is extended to the edge of the parking lane.

\section{Conclusion}

This study involves reviewing the usability of Sri Lanka's first differently abled road facility Bambalapitiya - Kollupitiya road 
section of the A2 road in Sri lanka. The study comprises of reviewing a facility design for differently able people based on international standard and behavioural study of trained visually impaired personal. Following aspects were considered in this study:

a) Understanding the world in the perspective of a visually impaired person.

b) Examining existing sets of guidelines related to differently abled road facilities.

c) Observing the behaviour of a visually impaired person travelling along the differently abled road facility.

d) Identifying positive outcomes and shortcomings of the facility.

e) Identifying ways of improvement.

The study team has observed that the defects in the facility were due to poor specification and workmanship. The set of guidelines itself did not give a proper description to explain the reasons for each act. This has led to many defects of the facility.

Improvement for this facility has been proposed based on the usability of the facility for visually impaired people while also serving mobility impaired people.

The guidelines given in "The Gazette of Democratic Socialist Republic of Sri Lanka (No 1,467/15 - 17/10/2006) [3]" covers most parts that is present in other sets of guidelines (NZ Transport Agency [2] Khechen [1], and Veter et al. [4]) but these guidelines doesn't seem to be prepared with much understanding of the abilities of differently abled people.

When a differently abled facility is developed it is essential that it is 100\% defect free. Especially, if it is a facility meant for visually impaired people. A differently abled person who travels more cautiously in general will loosen up his guard when travelling in such a road where a certification of safety is given. Therefore, a small mistake in facility can lead to a catastrophe.

Proposed design for crossing and bus stop should be incorporated in future to enhance the safety and usability of the facilities for differently abled people. Even if mostly the faults are pointed here, this differently abled facility is not at all a failure. Introducing such a facility itself is a trophy for the hearts of the differently abled people, especially, the war heroes. A new version of guidelines should be prepared with proper understanding of the abilities of differently abled people and incorporating the proposed design alterations.

\section{References}

1) Khechen, M., Accessibility for the Disabled - A Design Manual for a Barrier Free Environment, ESCWA, 2003.

2) NZ Transport Agency, RTS 14 Guidelines for facilities for blind and vision-impaired pedestrians, 2nd edition, Land Transport New Zealand, Wellington, 2007.

3) Sri Lanka, The Gazette of Democratic Socialist Republic of Sri Lanka, Disabled Persons' (Accessibility) Regulation No 1,467/15 - 17/10/2006, Colombo, 2006.

4) Veter, C. J., Sentinella, J., Rickert, T., Maunder, D., and Venkatesh, A., TRL Overseas Road Note 21 - Enhancing the mobility of disabled people: Guidelines for practitioners, Department of International Development (DFID), 2004.

5) Nebraska Commission for the Blind and Visually Impaired, "Cane Travel" video, Pathway to Independence Video Series, , Lincoln Ne, USA, Available at http://www.ncbvi.ne.gov/media/video/p athways-to-independence/index.html, Accessed on November 01, 2011. 
